Journal of Law \& Social Studies (JLSS)

Volume 2, Issue 2, pp 51-57, 2020

www.advancelrf.org

\title{
Conviction to Acquittal in Narcotic Cases by Higher Courts in Pakistan
}

\author{
Jibran Jameshed \\ Assistant Professor of Law \\ Islamia University Bahawalpur \\ Email: jibran_jamshed@yahoo.com
}

\begin{abstract}
This study is conducted with objective to investigate the reasons/factors behind the high number of acquittals in narcotic cases in the Higher Courts of Pakistan. Other objectives of this study includes the analysis of CNSA (Control of Narcotics Substance Act 1997) which deals with the narcotic/drug related cases in Pakistan, highlight the deficiencies in the investigation of police in narcotic cases in the light of latest judgments given by Higher Courts (High and Supreme Court) in Pakistan. The study also provides some suggestions to fill the lacunas and improve the conviction rate in narcotic cases in Pakistan. To understand the main factors responsible for the acquittal in the narcotic cases, this study analysis the latest judgments of High Courts and Supreme Court of Pakistan where accused were acquitted from the charges due to different reasons. The study also analyzes the Control of Narcotics Substance Act 1997 for this purpose. The results of study Highlights the most common reasons given by the Higher Courts in narcotic cases where accused were acquitted. The study also recommends some steps needed to improve the situation and increase the conviction rate in drug related cases.
\end{abstract}

Key Words: Narcotic Cases, Pakistan, Acquittal by Higher Courts, Criminal Justice System Pakistan

\section{Introduction}

The Higher Courts (High Court and Supreme Court) in Pakistan often acquit the accused persons convicted by the trial courts (normally Sessions Court in drug/narcotics cases). In majority of cases when convicted person file appeal against conviction in the High Court/Supreme Court, their sentence be reduced, or they get the acquittal from the charges. This phenomenon is not only encouraging the drug peddlers/criminals but also increasing the lawlessness in country. In Pakistan this is common phenomenon in all type of criminal cases where higher courts/appellate courts give benefit of doubts to the accused and tend to acquit them of charges. In narcotics cases, higher courts take more liberal and lenient view towards the accused while deciding their appeals.

In Pakistan Control of Narcotics Substance Act (CNSA) 1997 deals with the drug/narcotics crimes. According to CNSA, the trial court for narcotics offences must be a Special Court (which is normally an Additional and Sessions Judge). The Trial of narcotic cases is conducted by the Public Prosecutor who is deputed in the court for all trials conducted by that Court. After Trial Court completed the trial, the case finds its way into the appellate court, normally Concerned High Court. After High Court, some cases are referred to the Supreme Court of Pakistan.

\section{Aim of Study and Research Questions}

The study is conducted to investigate the major factors/reasons responsible for the acquittal in narcotic cases from the Higher Courts in Pakistan. This study is aimed to get the answers of following questions;

- Whether the Control of Narcotics Substance Act 1997 (CNSA) is comprehensive law?

- What are the different methods and procedures adopted by the Police during investigation of drug related cases?

- Why Higher Courts tend to acquit the accused convicted by the lower courts in drug cases?

- What are the major factors behind the acquittal of accused in higher courts?

- How to reduce the acquittal rate in higher courts? 


\section{Research Methodology}

This Qualitative Research based on the study of latest case laws of High Courts and Supreme Court of Pakistan. While analyzing the judgments of High Court and Supreme Court of Pakistan the study will highlight the deficiencies on the part of prosecution and investigation in the Criminal Justice System of Pakistan. The study also examines the Control of Narcotics Substance Act 1997, commonly known as CNSA, which deals with the crimes related with drugs/narcotics.

\section{Control of Narcotics Substance Act 1997 (CNSA)}

Preamble of CNSA clearly states that the purpose of this law is to "consolidate and amend the laws relating to narcotic drugs, psychotropic substance and control the production, processing and trafficking of such drugs and substances". Another purpose of this law is to regulate the treatment and rehabilitation of narcotics addicts.

This Act prohibits the "cultivation of any cannabis plant, coca bush or opium poppy or gather any portion of cannabis plant, coca bush or opium poppy". The CNSA also provides that Possession of narcotics drugs, Import or Export of narcotic drugs and trafficking or financing the trafficking of narcotic drugsare prohibited and punishable crimes. If anyone commits any of the above-mentioned crimes, he must be punished under section 9 of the Act which provides different punishments for the different quantities of the drugs. The strictest punishment is the Death or Imprisonment for life, if the drug quantity exceeds One Kilogram. It shows that the Act provides strict punishments for the drug related offences.

CNSA also gave vast powers to the Police and Investigation agencies in drug related cases. Investigating officer has power to enter and search for the drugs, arrest accused without warrant, power to seize the and arrest the accused in public places, power to stop and search any conveyance and perform undercover and controlled operations. Although the law gave vast powers to the investigation officer of cases falls under this Act, yet it also places some restrictions and even punishment for the vexatious entry, search, seizure or arrest of innocent person.

The law also provides that no bail be granted to an accused person charged with an offence under this Act or under any other law relating to the narcotics where the offence is punished with death. It shows that the law is strict and even the concession of bail is not allowed in certain circumstances.

Another important point in CNSA 1997 is that it made police officialscompetent witnesses. The provisions of Code of Criminal Procedure, 1898, except those of section 103, shall, mutatis mutandis, apply to all searches and arrests. Section 103 of Cr.P.C. require the presence of independent private witnesses in search made by the police but section 25 of CNSA 1997 excludes the operation of section $103 \mathrm{CrPC}$ in the narcotic cases. The main reason behind this section is that private people seldom come forward as witnesses against the influential and dangerous drug peddlers; hence police witnesses are made competent by CNSA 1997.

The above discussed are few of the most important points given in the CNSA 1997. The is detailed and very comprehensive in this regard and provides all other details like freezing and forfeiture of assets, establishment of special courts, treatment of rehabilitation of drug addicts, National fund for control of drug abuse and international cooperation in narcotic offences. All the above discussed facts prove that the CNSA 1997 is comprehensive, detailed and complete law and its true implementation can eradicate the evil of narcotics from the society.

\section{Some Common Reasons for theApproach of Higher Courts in Narcotic Cases}

First, Judges or Higher Courts are much more trained and professional than the judges of lower courts. They decide the appeals while considering every minute detail which are often not considered by the trial courts in narcotic cases.

Secondly the mind set of High Court judge is very much inclined towards the "benefit of doubt" to the accused. In Pakistan's Criminal Justice System, accused is the favorite child of law and it is settled maxim that, it is better to acquit the hundred guilty persons than to convict one innocent person. Judge of higher courts are more inclined towards this maxim and gave benefit of smallest doubt to the accused.

Thirdly the quality of investigation by police or other law enforcing agencies is very poor in the narcotic related cases. The investigation officers are not trained in modern investigation methods and techniques. Ill-equipped and untrained investigation officers play a vital role in the later acquittal of accused person in narcotic cases.

Independent Provincial Prosecution Departments in Pakistan are recently established and still in the early phase of their existence. Although the level of prosecution is improving with time, yet lot of work need to be done in this 
regard. There is need to train and equip the prosecutors dealing with the prosecution of narcotic cases in Pakistan. Role of Prosecutor at investigation stage must be enhanced because a bad investigation destroys the foundation of case which later results in the acquittal of accused by higher courts.

\section{Important Cases of Supreme Court}

There are many case laws of Supreme Court of Pakistan where court acquits the person convicted by the trial court in drug/narcotic cases.

\subsection{State vs. Imran Nazir - 2019 SCMR 1227}

In this case Supreme Court stated in its judgment that accused and co-accused were alleged to be carrying $2800 \mathrm{~kg}$ of charas in a vehicle. Trial Court convicted them under Section 9(C) of the CNSA 1997 and sentenced them to imprisonment for life, whereas the vehicle was confiscated in favor or the state. High Court acquitted the accused and co-accused on the ground that the prosecution witnesses failed to point out as to who was driving the vehicle when Anti-Narcotics Force contingent intercepted them. Held, that in the presence of two individuals (accused and coaccused) in the cabin it was incumbent upon the witnesses to unambiguously point out the person on the steering wheel in order to establish conscious possession of the seized narcotic. In the face of wavering positions taken by the prosecution itself, accused and co-accused could not be denied the benefit of the doubt. Appeals against acquittal of accused and co-accused were dismissed, however the order for forfeiture of vehicle impounded was kept intact.

\subsection{Kamran Shah vs. State - 2019 SCMR 1217}

In this case Supreme Court observed that situation about Safe custody of contraband substance by police. Case record shows that custody of recovered substance at the local police station hand not been established by the prosecution during the trial. Moharrir had been produced as witnesses in the trial court by the Prosecution but he had said nothing about receipt of the case property or its safe custody by him. Where safe custody of the recovered substance was not established by the prosecution it could not be held that the prosecution had succeeded in the establishing its case against an accused person. Convictions and sentences of the accused persons given by the lower courts were set aside and they were acquitted from all charges due to benefit of doubt.

Where safe transmission of the samples of the recovered substance was not established by the prosecution it could not be held that the prosecution had succeeded in establishing its case against an accused person.

Narcotics recovered from the secret cavities of the vehicle. Requirement to establish conscious possession of the contraband substance.It is incumbent upon prosecution to establish conscious possession of the contraband substance on the part of the accused persons but no evidence worth its name hand been brought on the record-accused acquitted from the charge.

\subsection{Razia Sultana vs. State - 2019 SCMR 1300}

Safe custody and transmission of samples of the alleged drug from the police to the chemical examiner- in cases where the chain of custody was broken, the report of the chemical examiner lost its reliability making it unsafe to support conviction. In this case the sample of narcotic was dispatched to the Government Analyst for chemical Examination through and officer of Anti-Narcotics Force, but the said officer was not produced to prove safe transmission of the sample from the police to the Chemical Examiner. Chain of custody this stood compromised and it would be unsafe to rely on the report of the Chemical Examiner. Conviction and sentence of the accused was set aside in circumstances.

\subsection{State vs. Abul Ali - 2019 SCMR 1102}

In this case Supreme Court held that there was no explanation provided for the discrepancy between the date of accused's arrest and his remission into police custody for registration of criminal case. Furthermore, the contradictions in the statements of the two of the prosecution witnesses were not trivial.Charges against the accused were not free from doubt. Appeal against acquittal of the accused was dismissed accordingly.

\subsection{Minhaj Khan vs. State - 2019 SCMR 326}

Conviction of accused primarily rested on the testimonies of the two police officials/eyewitnesses and one of them was also the complainant. Glaring discrepancies were found in the testimonies of the said two eyewitnesses. Said witnesses in their statements showed purported lack of knowledge about certain aspects of the case which they ought to have remembered. Accused was acquitted of the charge under section 9(c) of CNSA 1997. 


\subsection{Abdul Ghani vs. State - 2019 SCMR 608}

Safe transmission of samples to the Chemical Examiner not established. In a case where safe custody of the recovered substance or safe transmission of samples of the recovered substance was not proved by the prosecution through independent evidence, it could not be concluded that the prosecution had succeeded in establishing its case against the accused beyond reasonable doubt. In this case admittedly the Moharrir of the said police station had not been produced before the Trial Court to depose about the safe custody of the recovered substance. Head constable who had delivered the samples of the recovered substance at the office of the Chemical examiner had also not been produced during the trial so as to confirm convictions and sentences of the accused persons recorded and upheld by the court below were set aside in such circumstances and they were acquitted of all charges due to benefit of doubt.

\subsection{Khair ul Bashar vs. State - 2019 SCMR 930}

Government analyst report, whether prosecution should be allowed re-testing of samples in case of deficient report prepared by the Government analyst. Held, that re-testing of the drug, in case of deficient report would amount to giving a premium to the prosecution for its mistakes and lapses. Besides, there was likelihood that the chain of custody of the alleged drug was compromised with the passage of time.

\section{Important Cases of High Court}

\subsection{Gul Hassan vs. State - 2019 PCrLJ 957 (Balochistan)}

Seizure of narcotic- Benefit of doubt, Chemical Report, Appreciation of Evidence, sample sent after delay- effectrecord showed that alleged recovery was affected on 1.1. 2016 but forensic science laboratory report revealed that the samples were received by the expert on 26.1.12016 with delay of about 25 days and such delay had not been explains - Rule 4(2) of the Control of Narcotic Substances (Government Analyst) Rules 2001 provided that such should be completed within 72 hours of recovery - no plausible explanation was presented by the prosecutor in that regard said delay was fatal to the prosecution case - prosecution had failed to examine the police officer who had transported the samples to Chemical Examiner so that he could have been cross examined on the point as to in whose custody the sealed parcels of the samples of charas were lying about 25 days which had made the case of prosecution doubtful. Safe custody and $\mathrm{s}$ are transmission of the seized narcotic had not been established hence accused was acquitted.

\subsection{Javed vs. State - 2019 PCrLJ Note 112 (Sindh)}

In this case High Court said that Charas was recovered on 05-12-16 and samples were submitted to Chemical Examiner on 09-12-16 after an unexplained delay of four days when the law required such samples to be sent for chemical analysis within three days of recovery. Record transpired that the in charge of the Malkhana had not been examined and the Police Constable who delivered the samples to the Chemical Examiner had not been examined as to its safe custody. High Court acquitted the accused in this case from charges.

\subsection{Farzand Ali vs. State - 2019 PCrLJ 1207 (Lahore)}

In this case court observed that Case Property was recovered on 25-08-09 by Rangers but statedly deposited in the warehouse on 29.08.09. Said fact showed that neither case property not any sample was received in the police station. Similarly, the alleged samples were never sent by the Investigating Officer of the case to the office of Chemic Examiner, but it was sent by Inspector Rangers. Circumstances established that safe custody of the case property and samples and then onward transmission of said samples to the office of Chemical Examiner could not be proved by the prosecution. In this case, Court converted the conviction of trial court into acquittal.

\subsection{Samiullah VS. State - 2019 MLD 1377 (Balochistan)}

In this case court converted the conviction of trial court to acquittal because court observed that samples were sent for analysis after a delay of 20 days. Investigation officer failed to tender any plausible explanation for the delay in sending the samples for analysis. Safe custody of contraband was not established and hence accused be acquitted from all charges.

\subsection{Nasir Rajpoot VS. State - 2019 MLD 1021 (Sindh)}

IN this case High Court observed that alleged charas was kept in the Malkhana for five days. Safe custody of the charas during said period had not been established. Charas was allegedly dispatched to the Chemical Examiner through 
Police Constable but safe transit had not been established through said Police Constable as he hand not been examined. Hence High Court set aside the conviction and sentence passed by the trial court in this case.

\section{Major Reasons given by the Superior Court for acquittal of accused in drug cases}

Followings are some important reasons given by the Higher Courts in their judgments for the acquittal of accused involved in drug/narcotics cases.

\subsection{Delay in Lodging First Investigation Report(FIR)}

In State vs. Abdul Ali Supreme court acquit the accused because no explanation was provided for discrepancy that there is delay between arrest of accused and registration of FIR against accused. There are number of high court judgments on this point and it is settled rule that delay in lodging of FIR is fatal for the case of prosecution especially in narcotic cases.

It is duty of Police Department to ensure that in all cases of narcotics FIR should be lodged as early as possible because at later stages it becomes reason of accused's acquittal.

\subsection{Contradictions in Testimonies of Witnesses}

Contradiction in the testimonies of the witnesses is also one of the main causes of acquittal of accused in narcotics cases by higher courts. In narcotic cases usually all witnesses are Police Officials including complainant. The reason is that no private person wants to become witness in such cases and even Control of Narcotics Substance Act 1997 itself provide that there is no need of private witnesses in narcotic cases.In many cases Police witnesses are not well prepared due to different reasons i.e. lack time, lack of interest, ulterior motives, lack of interest of prosecutor etc. which ultimately results in the acquittal of accused by Higher Courts.

In Minhaj Khan vs. State Supreme Court acquit the accused because there were glaring discrepancies between the testimonies of witnesses.

Police Department needs to pay attention of this issue because in drug cases all the witnesses are usually police officers. It is necessary that the witnesses completely understand the case before appearing in the court to face the cross examination of defense counsel. Prosecutor need to prepare the witness before the start of testimony in the court.

\subsection{Submission of Samples to the Chemical Examiner}

While looking at some of the latest judgment of Higher Courts in narcotics cases we can conclude that collection of samples from the recovered narcotics and its submission to the Chemical Examiner is of paramount importance. In Kamran Shah vs. StateSupreme Court observed safe custody and safe transmission of samples is necessary for the conviction of accused. In Razia Sultana vs. StateSupreme Court held that where safe custody and transmission of samples not established rely can be based on the Chemical Examiner report. In Abdul Ghani vs. State Supreme Court acquit the accused because the head constable who delivered the samples to the office of Chemical Examiner was not produced in the court as witness.

To establish a safe custody and transmission of the samples to the Chemical Examiner it is necessary that testimony of the Police Officer in charge of Malkhana where sample deposited must be recorded during trial. It is also necessary to record the statement of Police Official who take the samples from Malkhana and deposited it to the Office of Chemical Examiner. These two witnesses play major role in establishing the safe custody and transmission of samples to the Office of Chemical Examiner

In Zahida Perveen vs. State, Lahore High Court observed that safe custody of case property from recovery to its production in the court was not proved, hence appeal of accused person allowed because safe custody of case property and its sample is necessary for conviction. Recovery in such cases is not mere corroborating piece of evidence rather it constitutes the charges and entails punishment, not proving the safe custody in such cases is fatal for the prosecution.

\subsection{Delay in Sending the Sample to the Chemical Examiner}

In Gul Hassan vs.State High Court acquit the accused because samples were sent to the office of Chemical Examiner after 25 days and there is no explanation for such delay. According to Rule is it obligatory to send the samples to the office of Chemical Examiner within 72 hours. In Javed vs. State, Court observed that samples were dispatched after delay of four days and Head constable who oversees Malkhana was also not produced as witness in the court and 
acquit the accused on basis of these reason. In Samiullah vs. State High Court acquit the accused from charges because samples were deposited in the Office of Chemical Examiner after delay of 20 days. In Nasir Rajpoot VS. State High Court acquit the accused because samples remained in the Police Custody for five days without any explanation before their onward submission to office of Chemical Examiner.

In Farzand Ali vs. State Rangers arrested the accused with drugs but instead of Police Investigation Officer, Inspector Rangers sent the samples to the office of Chemical Examiner. Safe custody and transmission were not established, and High Court acquits the accused due to above mentioned reasons.

It is duty of Police to send the samples in narcotic cases to the Chemical Examiner. There must be strict rules regarding this point and Police Department needs to ensure that these rules must be followed with spirit. Prosecution Department can also play positive role in this regard if they were given some powers to direct the investigation Officers at the investigation stage.

\subsection{Police Witnesses in Case of Narcotics}

Section 25 of the Control of Narcotics Substance Act 1997 excludes the operation of section 103 CrPC. in the narcotic cases. It means there is no need to engage the private independent witnesses in narcotic cases and Police Officials are competent witnesses in the Narcotic cases. Although the engagement of private witnesses is excluded by section 25 of CNSA 1997, yet Higher Courts in their judgment time and again stated the importance of Private witnesses in the narcotic cases.

For example, in one case High Court observed that provisions of Sec 25 of CNSA exclude applicability of section 103 of CrPC. but such exclusion does not authorize the Investigation Officer of Police to absolutely exclude independent witnesses in all circumstances.

In recent judgment of SupremeCourt, it was held that Police witnesses, functionaries of the state were no less credible witnesses to drive home the charge. Their evidence was subject to the same standard of proof and principles of scrutiny as applicable to any other category of witnesses and in absence of any animus, infirmity or flaw in their deposition, their statements could be relied upon without demur.

Although there are judgments in favor and against the association of independent witnesses, yet Investigation Officers needs to engage independent witnesses wherever possible to strengthen the case of Prosecution.

\section{Conclusion}

We can conclude that Control of Narcotics Substance Act 1997 is comprehensive and detailed piece of legislation but the reason it fails to eradicate the evil of drug menace from Pakistan is the implementation of this law. All the constituents of Criminal Justice System are responsible for the weak implementation of the law, but Investigation Agencies and Police especially fail to implement this law due to their structural weaknesses and chronic corruption. Faulty and weak Investigation of the Narcotic cases is the basic reason of this high acquittal rate in appellate courts. Another point is also worth mentioning that is the level of appreciation of evidence by the higher courts. While keeping in the mind the standard of Police Investigation in Pakistan, the criteria set by the higher courts for the evaluation of the evidence in narcotic cases is very high and not compatible. Some of the common reasons for the acquittal of accused in narcotic cases includes delay in lodging FIR, unprepared police witnesses, non-separation of samples from the recovered contraband, unsafe custody and transmission of samples to the Chemical Examiner, delay in sending the samples to Chemical Examiners, faulty investigation and lack of required interest on the part of Prosecution.

\section{References}

Abdul Ghani vs. State - 2019 SCMR 608

Control of Narcotics Substance Act 1997

Control of Narcotic Substances (Government Analyst) Rules 2001

Farzand Ali vs. State - 2019 PCrLJ 1207 (Lahore)

Gul Hassan vs. State - 2019 PCrLJ 957 (Balochistan)

Javed vs. State - 2019 PCrLJ Note 112 (Sindh) 
Kamran Shah vs. State - 2019 SCMR 1217

Minhaj Khan vs. State - 2019 SCMR 326

Muhammad Ishaq Ghazi vs. State - SCMR 146

Nasir Rajpoot vs. State - 2019 MLD 1021 (Sindh)

Razia Sultana vs. State - 2019 SCMR 1300

Samiullah VS. State - 2019 MLD 1377 (Balochistan)

State vs. Abul Ali - 2019 SCMR 1102

Zahida Perveen vs. State - 2019 PCrLJ 1491

2014 MLD 727 